\title{
Electron Microscopy Study of Molybdenum Disulfide Nanowires
}

\author{
Qiguang Li*, Wen-An Chiou**, Reginald Penner* \\ * Department of Chemistry, University of California, Irvine, CA 92697 \\ **Department of Chemical Eng. and Material Science, University of California, Irvine, CA 92697
}

Molybdenum disulfide, a typical layered semiconductor, has been widely used in lubricant, batteries, and catalysis industries. Since the discovery of $\mathrm{MoS}_{2}$ by wrapping $\mathrm{MoS}_{2}$ sheets [1], research of fabricating $\mathrm{MoS}_{2}$ nanotubes/nanowires has attracted many researchers [2,3] due to its unique structure and potential applications. This paper presents the morphological and internal structure study of the $\mathrm{MoS}_{2}$ nanowires synthesized by sulfurization of $\mathrm{MoO}_{\mathrm{x}}$ nanowires.

The fabrication of $\mathrm{MoO}_{\mathrm{x}}$ nanowire using an electrochemical step edge decoration method has recently been developed [4]. An overpotential was applied to the highly oriented pyrolytic graphite (HOPG) in aqueous $1 \mathrm{mM} \mathrm{Na}_{2} \mathrm{MoO}_{4}$ solution. Due to the preferred deposition of $\mathrm{MoO}_{\mathrm{x}}$ along the step edges of $\mathrm{HOPG}$, long and uniform $\mathrm{MoO}_{\mathrm{x}}$ nanowire arrays were formed. These $\mathrm{MoO}_{\mathrm{x}}$ nanowires were placed in $\mathrm{H}_{2} \mathrm{~S}$ atmosphere at elevated temperature for $7 \mathrm{hrs}$ and annealed in $\mathrm{N}_{2}$ or $\mathrm{H}_{2} \mathrm{~S}$ for $10-40 \mathrm{hrs}$. $\mathrm{MoS}_{2}$ nanowires on HOPG were directly examined by SEM. After sulfurization, part of the graphite was peeled off, leaving only part of the graphite surface directly contacted with $\mathrm{MoS}_{2}$ nanowires. A TEM grid was then gently pressed onto the graphite/ $\mathrm{MoS}_{2}$ nanowires boundary region. Some of the nanowires along the boundary were transferred onto the TEM grid for TEM imaging.

The SEM image (Fig.1) shows the synthesized $\mathrm{MoS}_{2}$ nanowire arrays on HOPG. The nanowires have diameters ranging from 30 to $300 \mathrm{~nm}$ with lengths up to $500 \mu \mathrm{m}$. Higher magnification images show that the wires are uniform along their entire length and continuous after the chemical conversion (Fig. 2 and 3). The nanowire morphology remains unchanged at relatively low annealing temperature $\left(500-700{ }^{\circ} \mathrm{C}\right.$ in $\left.\mathrm{N}_{2}\right)$. However, they begin to break into nanoparticles at higher temperature $\left(>800{ }^{\circ} \mathrm{C}\right.$ in $\left.\mathrm{N}_{2}\right)$.

The TEM results show that the internal structure of the nanowires displayed an ordered transition upon different sulfurization conditions. The low magnification TEM image (Fig. 4) shows the overall morphology of a nanowire, and is quite similar to that revealed by higher magnification SEM image (Fig. 3). At higher magnification as shown in Fig. 5, the nanowire appeared to consist of ribbon-like crystals after sulfurizing in $\mathrm{H}_{2} \mathrm{~S}$ at $500^{\circ} \mathrm{C}$ for $7 \mathrm{hrs}$ and annealed in $\mathrm{N}_{2}$ for additional $40 \mathrm{hrs}$. The ribbons usually have less than $10 \mathrm{MoS}_{2}$ atomic layers (002 plane), and are randomly interweaved with each other. The crystallinity was greatly improved after annealing at $700^{\circ} \mathrm{C}$ in $\mathrm{H}_{2} \mathrm{~S}$. More than $100 \mathrm{~nm}$ long and rather preferred oriented $\mathrm{MoS}_{2}$ ribbons/grains can be clearly seen around the edge of nanowires in the high resolution TEM image (Fig. 6). In general, individual ribbon inside the wire has 20-40 atomic layers, which is much larger than those annealed at $500^{\circ} \mathrm{C}$ in $\mathrm{N}_{2}$. Although the orientation of the ribbons was still randomly interweaved inside the wires, initial TEM results suggest that layered nanowire with preferred orientation along the long axis could be formed by changing the annealing conditions. More research is in progress.

\section{Reference}

[1] Y. Feldman et al., Science, 267 (1995) 222.

[2] W. K. Hsu et al., Am. Chem. Soc., 122 (2000) 10155.

[3] M. Remskar et al., Science, 292 (2001) 479.

[4] M. Zach, K. Ng and R. Penner, Science, 290 (2000) 2120

[5] This research was supported by the NSF \#CHE 0111557. 


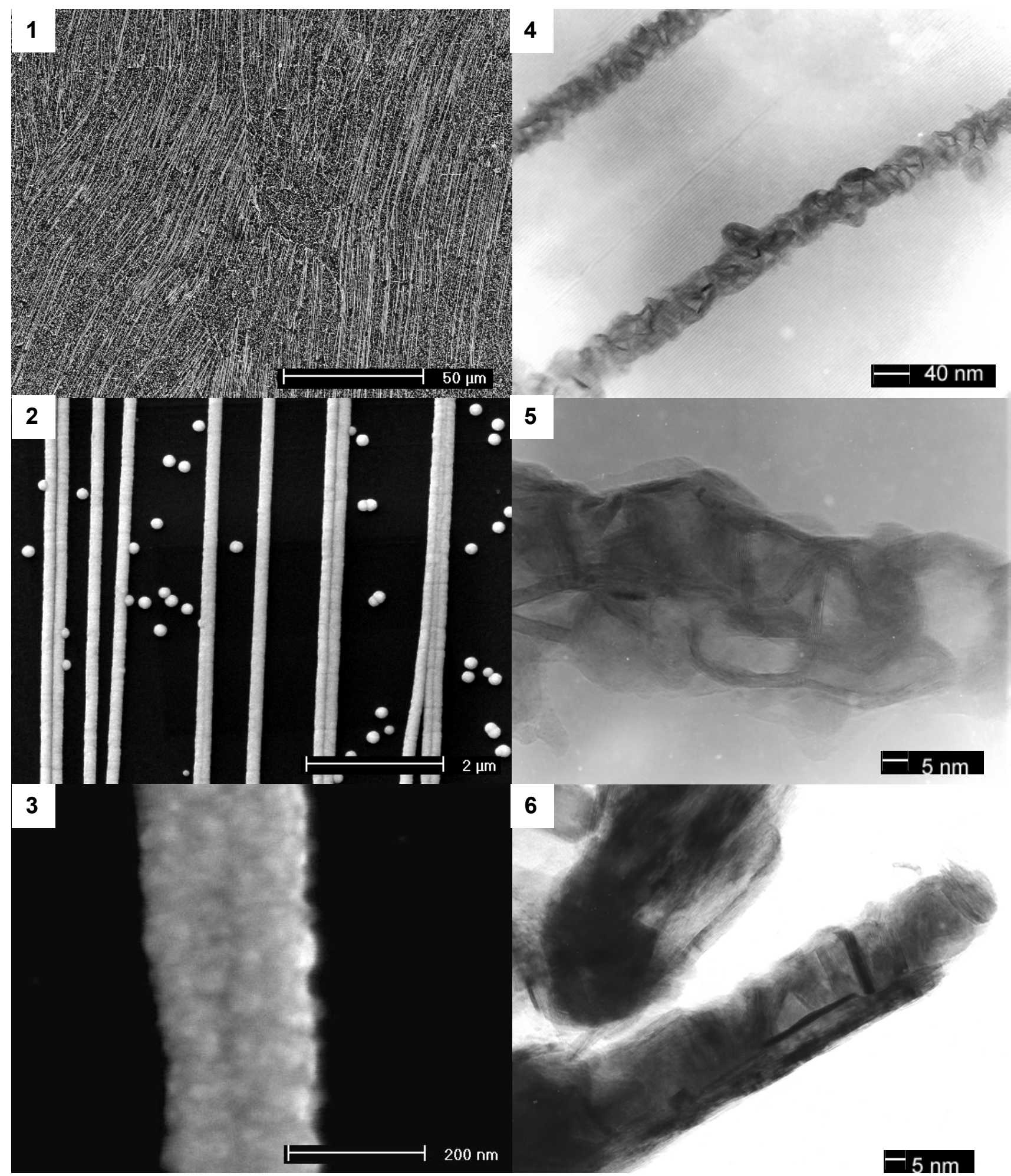

Fig. 1. Low magnification SEM image showing synthesized $\mathrm{MoS}_{2}$ nanowire arrays on HOPG.

Fig. 2. SEM close-up view of $\mathrm{MoS}_{2}$ nanowires.

Fig. 3. Higher magnification SEM view depicting nanowire with a rough surface.

Fig. 4. TEM micrograph of a $\mathrm{MoS}_{2}$ nanowire.

Fig. 5. HREM image showing fiber-like $\mathrm{MoS}_{2}$ randomly interweaved each other.

Fig. 6. HREM image depicting lattice fringes of somewhat lath-like $\mathrm{MoS}_{2}$ crystals. 